\title{
Por uma fé encarnada: resgatando a contribuição protestante para uma teologia pública e cidadã
}

Wanderley Pereira da Rosa

\section{Resumo}

Esta comunicação propõe apresentar a dimensão política e social da teologia construída na época da Reforma Protestante e a virada fundamentalista ocorrida no início do século XX que tornou grande parte do mundo protestante hermético ao ambiente social, aos avanços no conhecimento e ao diálogo inter-religioso. Imediatamente depois disso, também pretende analisar a igreja evangélica brasileira à luz desta realidade.

Palavras-chave: Pensamento Protestante; Fundamentalismo; Teologia Pública.

\begin{abstract}
This proposes to introduce political and social dimension of theology built at the time of the Protestant Reformation and the fundamentalist turned of the early twentieth century that made much of the Protestant hermetic ambient in his social environment, advances in knowledge and inter-religious dialogue. Immediately thereafter, also intends to analyze the Brazilian evangelical church in the light of this reality.
\end{abstract}

Keywords: Protestant Thought; Fundamentalism; Public Theology. 


\section{Introdução}

Considerando-se os quatro grandes ramos da Reforma quais sejam, o luterano, o calvinista, o anabatista e o anglicano e, em consonância com um grande número de pensadores e teólogos podemos sustentar que o Pensamento da Reforma mantém estreitos vínculos com a modernidade nascente. Será, talvez, a primeira manifestação religiosa da modernidade. Assim, por exemplo, Troeltsch afirma que "o protestantismo encerrava aspirações que iam de encontro ao mundo moderno... e que lhe permitiam amalgamar-se com o novo". ${ }^{1}$ O novo edifício que aí começa a ser construído contrapõe ao dogmatismo medieval o uso da razão e a dúvida como método investigativo. Pelo menos, é esta a proposta do filósofo e matemático francês René Descartes (1596-1650). Ao contrário da Idade Média quando o dogma já antecipava em que as pessoas deveriam acreditar, este novo período, conhecido como Idade Moderna encontra no ceticismo metodológico seu caminho para a elaboração do conhecimento. Esta nova era racionalista, empirista, iluminista, positivista e pragmática exclui, por assim dizer, o elemento religioso. Em face disso, Rubem Alves pôde afirmar que "Deus passou a ter problemas habitacionais crônicos. Despejado de um lugar, despejado de outro... Progressivamente foi empurrado para fora do mundo. Para que os homens dominem a terra é necessário que Deus seja confinado aos céus". ${ }^{2}$ As crenças religiosas ficaram restritas a vida privada. Esse "desencantamento do mundo" (Max Weber), esse "exílio do sagrado" (Roger Bastide) consolidou essa nova era na história do mundo ocidental. A secularização da consciência proporcionou a libertação do mundo das ciências naturais dando início a um avanço científico jamais experimentado pela humanidade. ${ }^{3}$

Esse novo zeitgeist, segundo Hegel, inicia-se com a Reforma e consolida-se com o iluminismo e a Revolução Francesa ${ }^{4}$. Nesse sentido, a Reforma é vista como protagonista neste longo processo de secularização do sagrado.

\footnotetext{
${ }^{1}$ TROELTSCH, E. El Protestantismo y El mundo Moderno. México: FCE, 1951, p. 65. apud CAVALCANTE, Ronaldo. A Cidade e o Gueto. Introdução a uma Teologia Pública Protestante e o desafio do neofundamentalismo evangélico no Brasil. São Paulo: Fonte Editorial, 2010. p. 56.

${ }^{2}$ ALVES, Rubem. O Que é Religião. São Paulo: brasiliense, 1981, p. 40.

${ }^{3}$ ROSA, Wanderley. O Dualismo na Teologia Cristã - a deformação da antropologia bíblica e suas conseqüências. São Paulo: Fonte Editorial, 2010. p. 109, 110.

${ }^{4}$ CAVALCANTE, 2010, p. 55-56.
} 
$\mathrm{Ou}$, como afirma Ronaldo Cavalcante "o protestantismo articularia, com base na liberdade do individuo, uma nova estética religiosa oferecendo-a ao homem ocidental como alternativa para uma espécie de sentido religioso secularizado da existência humana". ${ }^{5}$ A Reforma pode ser compreendida, portanto, tanto como conseqüência quanto causa da modernidade.

De que forma a Reforma Protestante contribui para o surgimento da Modernidade? Conforme Cavalcante ${ }^{6}$, duas conquistas do protestantismo foram essenciais para a fundamentação deste novo mundo: em primeiro lugar o conceito de Pessoa, de indivíduo, de subjetividade. O princípio fundante do protestantismo conhecido como "sacerdócio universal de todos os crentes" é um de seus desdobramentos. Este não é um conceito presente no medievo. Os habitantes do edifício medieval se assemelhavam mais a soldados treinados para marchar em perfeita harmonia sob a ordem autoritária do comandante. Nesse processo de construção do conceito de Pessoa, o pietismo alemão do século XVII constituiu-se em um importante fator de fixura da subjetividade. A esse respeito afirma Paul Tillich: "o Pietismo é a reação do lado subjetivo da religião contra o lado objetivo". ${ }^{7}$

Uma segunda conquista da Reforma foi o princípio da Liberdade. Essa liberdade expressava-se como liberdade de consciência, liberdade de exame e liberdade de expressão. Decorre dessas duas conquistas os fundamentos da Reforma Protestante que também serviram como fundamento da Modernidade. Ainda segundo Cavalcante, podemos resumir estes novos paradigmas na redescoberta do texto bíblico com o surgimento das traduções a partir dos originais para a língua do povo. As Escrituras tornam-se assim, o centro da fé protestante. Em segundo lugar, a renovação da teologia expressa na máxima protestante "sola gratia, sola fide, sola scriptura". Ora, este novo paradigma hermenêutico colocava em xeque o dogmatismo medieval e a autoridade da Igreja como única capaz de interpretar corretamente o texto. Em terceiro lugar a inserção na sociedade, o que Max Weber chamou de "ascetismo mundano". Esta inserção era reflexo da secularização e da abolição da distinção sagrado-profano conforme formulada na Idade Média. Em quarto lugar a dignificação do trabalho e da atividade mundana. Neste ponto, a contribuição de Calvino foi exemplar. Como pude descrever em

\footnotetext{
${ }^{5}$ CAVALCANTE, 2010, p. 57.

${ }^{6}$ CAVALCANTE, 2010, p. 64.

${ }^{7}$ TILLICH, Paul. História do Pensamento Cristão. São Paulo. ASTE, 2000. p. 279.
} 
outro texto "para ele a ascese não é para fora do mundo (como na concepção grega e monástica), mas, um "ascetismo secular". Conforme Tillich, esse ascetismo intramundano caracterizava-se de duas maneiras: limpeza e lucro por meio do trabalho". ${ }^{8}$ Em quinto lugar, a separação entre Igreja e Estado, com notável contribuição dos anabatistas que foram os primeiros a perceber a necessidade de estabelecer de forma diferenciada o estatuto de cada um desses entes. Em sexto lugar, o desenvolvimento do parlamentarismo e do espírito democrático. Com as novas idéias acerca do governo eclesiástico vêm, a reboque, a confrontação das monarquias absolutistas européias da qual, a Revolução Gloriosa na Inglaterra do século XVII é uma das principais conseqüências. Em sétimo lugar, o avanço da ciência moderna, sobretudo, a partir do século XVII também como resultado do processo de secularização9.

Em tudo isso vemos a contribuição protestante para a construção da modernidade. Sua proposta é a de uma religião cidadã, de uma teologia pública, de uma fé secularizada. O Protestantismo clássico levanta-se contra a ordem institucionalizada, engessadora da consciência e da expressão pessoal ${ }^{10}$.

Como exemplo desta dimensão social e política do pensamento protestante, vale aqui destacar a figura de Walter Rauschenbusch líder do movimento chamado "evangelho social". Rauschenbusch era pastor batista em Nova Iorque no início do século XX e lá foi impactado pelas deploráveis condições econômicas e sociais vividas pela comunidade que pastoreava. $\mathrm{O}$ local era chamado pelos próprios moradores de "cozinha do diabo" teologia e prática pastoral nasceram, assim, da reflexão teológica a partir das condições de sofrimento do povo. Rauschenbusch baseava suas convicções na Bíblia, sobretudo, na leitura dos profetas do Antigo Testamento e no anúncio do Reino de Deus feito por Jesus e registrado nos evangelhos. Para ele santidade tinha a ver com as ações em favor da justiça social.

A mística parece o caminho mais rápido para a comunhão com Deus. Sem dúvida nasceram dela sobre condições favoráveis, um espírito de serviço, humildade e coragem. O seu perigo é que ela pode isolar. [...] só que Deus [...] nos criou como seres comunitários e a forma mais alta

\footnotetext{
${ }^{8}$ ROSA, 2010, p. 83.

${ }^{9}$ CAVALCANTE, 2010, p. 64, 65.

${ }^{10}$ CAVALCANTE, 2010, p. 73.

${ }^{11}$ Cf. HENDERS, Helmut. "É a Tarefa da Igreja Motivar a Sociedade para a Ação": Do contínuo significado de Walter Rauschenbusch. In: Simpósio 48. São Paulo: ASTE, 2008. p. 101.
} 
de perfeição não nasce do isolamento, mas do amor [...] o misticismo não representa a forma mais madura da santificação [...] mas o aspecto eternamente jovem, infantil e na sua essência imatura da vida religiosa. [...] Eu acredito na oração e na meditação na presença de Deus. Quando a alma fica perceptiva por Deus perdem-se o medo, a vontade de acumular riquezas e quaisquer ambições egoístas [...]. Quando o homem tem que enfrentar trabalho duro ele necessita receber dessa fonte silenciosa. Mas o que ele recebeu dessa fonte deve ser investido. A santificação pessoal deve servir o Reino de Deus. ${ }^{12}$

Com tal conceito de espiritualidade integral, não havia espaço no pensamento de W. Rauschenbusch para o dualismo platônico. Ele afirmava que Jesus, em seu ministério e pregação do Reino de Deus, superou as tentações de uma santidade baseada em misticismo, ascetismo e transcendentalismo ${ }^{13}$.

O teólogo do Evangelho Social convenceu-se que os graves problemas sociais não seriam resolvidos simplesmente pela conversão de indivíduos um após o outro. Era necessária uma mudança na própria estrutura da sociedade ${ }^{14}$. A pregação do evangelho não deveria visar tão-somente a conversão individual e a moralidade individualista, mas, seu foco deveria ser a proclamação e implantação do Reino de Deus, um Reino de justiça para todos ${ }^{15}$. Em resposta, "fundou um movimento denominado [...] Fraternidade do Reino. [...] Posicionava-se contra o capitalismo tipo laissez-faire, preconizando uma democracia não somente política, mas também econômica; [...] participação dos trabalhadores no lucro da empresas; fortalecimento dos sindicatos etc". ${ }^{16}$ Muitos avanços foram feitos como conseqüência das influências do Evangelho Social sendo incorporado ao trabalho missionário de muitos a preocupação com melhorias nas áreas agrícolas, médicas e educacionais do povo ${ }^{17}$.

O movimento fundamentalista, herdeiro da ortodoxia protestante, iniciado em princípios do século XX nos Estados Unidos representou uma virada obscurantista patrocinadora de uma atitude pseudo-intelectual e de outro lado de uma espiritualidade desencarnada e dicotômica. O fundamen-

\footnotetext{
${ }^{12}$ RAUSCHENBUSCH, apud HENDERS, 2008, p. 106.

${ }^{13}$ HENDERS, 2008, p. 107.

${ }^{14}$ Cf. GONZALEZ, Justo L. Uma História do Pensamento Cristão. Da Reforma Protestante ao Século 20. Vol. 3. São Paulo: Cultura Cristã, 2004. p. 389.

${ }^{15}$ Cf. GONZALEZ, 2004, p. 390.

${ }^{16}$ KLEIN, Carlos Jeremias. A Teologia Liberal e a Modernidade. In: Etienne Alfred Higuet (org.). Teologia e Modernidade. São Paulo: Fonte Editorial, 2005. p. 53-54.

${ }^{17}$ Cf. WALKER, Wiliston. História da Igreja Cristã. São Paulo: ASTE, 2006. p. 282.
} 
talismo diferia da ortodoxia protestante na incorporação de novos elementos teológicos, na exacerbação de seu dogmatismo e no obscurantismo intelectual. O movimento apresentou-se como o Cristianismo verdadeiro, incondicionalmente fiel às Escrituras as quais interpretava de forma literalista sem admitir quaisquer métodos de investigação exteriores a ela.

Parece que o marco inaugural do Fundamentalismo foram duas importantes publicações do início do século XX: a Bíblia de Scofield (1909) e uma série de livretos conhecidos como Os Fundamentos (1909-1915). A Bíblia de Scofield popularizou a teoria pré-milenista dispensacionalista de John N. Darby, também conhecida como darbysmo. O dispensacionalismo sustenta a existência de sete dispensações, ou formas diferentes de Deus se relacionar com a história humana. Esta teoria estava em profunda sintonia com os apocalipsismos que percorreram todo o século XIX. "O pré-milenismo incompatibilizou a Igreja com qualquer atividade de melhoria social". ${ }^{18}$ Sua tarefa deveria ser somente a de salvar almas.

A publicação de Os Fundamentos visava marcar posição clara contra a teologia liberal. Financiado por cristãos fundamentalistas ligados ao setor do petróleo, milhares de cópias foram enviadas gratuitamente para os principais seminários teológicos, pastores, líderes denominacionais e professores de teologia. Os fundamentalistas de primeira hora sustentavam cinco pontos inegociáveis em matéria de crença cristã: a inerrância das Escrituras, o nascimento virginal, a morte vicária, a ressurreição física de Jesus e a volta de Cristo ${ }^{19}$. Associações de fundamentalistas foram organizadas ${ }^{20}$. A Associação Cristã Mundial dos Fundamentos fundada em 1919 pelo ministro W.B. Riley acrescentou à lista de fundamentos o pré-milenismo dispensacionalista e o antievolucionismo. Esses acréscimos e o acirramento de posições acabaram provocando um racha dentro do próprio movimento ${ }^{21}$. $\mathrm{O}$ historiador Roger Olson afirma:

\footnotetext{
${ }^{18}$ MENDONÇA, Antônio Gouvêa. O Celeste Porvir: A Inserção do Protestantismo no Brasil. São Paulo: Pendão Real/ASTE/Ciências da Religião, 1995. p. 68.

${ }^{19}$ É bem verdade que esta lista não encontrava unanimidade nem no ambiente conservador, sofrendo variações que podiam incluir a Trindade e a queda da humanidade no pecado, dentre outros pontos. Mas, a questão central para todos era a inerrância das Escrituras.

${ }^{20}$ Como por exemplo, a Associação Cristã Mundial dos Fundamentos (1919) liderada por W.B. Riley e a Associação dos Fundamentos (1920) de Curtis Lee Lewis. Cf. OLSON, Roger. História da Teologia Cristã. 2.000 anos de tradição e reformas. São Paulo: Vida, 2001, p. 576-577.

${ }^{21}$ Cf. OLSON, 2001, p. 576-579.
} 
Muitos estudiosos [...] acreditam que, ao adotar o antievolucionismo como bandeira e ao incluir opiniões relativamente secundárias, como o pré-milenarismo, à sua agenda política e insistir na inerrância absoluta e aliada à uma hermenêutica literalista, o fundamentalismo condenou-se à obscuridade teológica. ${ }^{22}$

Nas décadas de 1940 e 1950 várias posições foram assumidas pelo movimento como a crença na semana da criação literalmente em sete dias aliada à crença na Terra jovem; o separatismo bíblico considerando todos os não fundamentalistas como hereges, apóstatas ou simplesmente filhos do demônio; apoio incondicional ao sionismo; anticomunismo com apoio na década de 1950 ao Macarthismo.

Para os fundamentalistas, a verdade religiosa é pressuposto para a ação política. Seu alvo é a sociedade perfeita. Esta só se estabelece quando todos se submetem à verdade religiosa, assim como ditada pelo Espírito Santo e fixada nas páginas inerrantes, incapazes de erro, do texto bíblico. Concluímos que o fundamentalismo, mais do que algumas radicalizações da ortodoxia protestante, vai contra o espírito da Reforma Protestante no que tem de intolerante, rígido e fechado. No universo fundamentalista tudo já está decidido gerando estagnação intelectual e esterilização da criatividade humana. "Parece que essa ambigüidade está no cerne do protestantismo: ao mesmo tempo que conduz idéias libertárias e proclama o livre exame, tende a enrijecer-se no dogmatismo". ${ }^{23}$ Ainda que se apresente como o supra-sumo do Cristianismo, o fundamentalismo sustenta a dicotomia platônica entre corpo e alma provocando um reducionismo na tarefa da Igreja. Esta passa a se restringir à tarefa espiritual de salvação das almas. A Igreja torna-se a-histórica sem abertura para o social. Sua idéia de santidade é negativa, sinônimo de separação do mundo. Sua discriminação daqueles que não pensam em termos fundamentalistas é anti-cristã e nega a ética do Reino baseada no amor.

\section{Evangélicos e Sociedade Brasileira}

O certo grau de sucesso quando da chegada dos Protestantes ao Brasil no século XIX em função de representarem naquele momento uma alternativa cultural, liberal e modernizante ao modelo católico conservador, deu lugar

\footnotetext{
${ }^{22}$ OLSON, 2001, p. 579.

${ }^{23}$ MENDONÇA, 1995, p. 54.
} 
à estagnação e isolamento da sociedade brasileira. $\mathrm{O}$ que outrora era um sopro renovador de cultura, agora não passava de conservadorismo religioso sem relevância social; tornou-se uma subcultura. O protestantismo brasileiro não acompanhara as mudanças nacionais e nem as mundiais com a nova configuração geopolítica do pós-guerra. Para esta nova conjuntura global, era necessário uma nova teologia, ou uma nova hermenêutica que desse conta dos desafios contemporâneos. Na Europa essa nova hermenêutica estava sendo articulada por alguns importantes teólogos como Karl Barth, Emil Brunner, Dietrich Bonhoeffer, Paul Tillich, Jürgen Moltmann ${ }^{24}$, dentre outros. Nos Estados Unidos devemos destacar o papel desempenhado pelos irmãos Niebuhr e Harvey Cox.

José Bittencourt Filho aponta para os caminhos percorridos a partir dessa encruzilhada existencial na qual os protestantes se encontraram em fins da década de 1950. Segundo ele, uma parte dos evangélicos brasileiros percebeu a necessidade de reconfigurar o protestantismo para além do denominacionalismo e colocá-lo a serviço da sociedade brasileira ultrapassando suas funções meramente religiosas ${ }^{25}$. Surgiu a partir daí um protestantismo ecumênico. Outra parte entendeu que o melhor era renovar seus antigos princípios pietistas, reafirmar sua ética individual e não social, investir contra o liberalismo teológico nos seminários, emparelhar-se com as elites conservadoras brasileiras, e incorporar o fundamentalismo teológico à sua agenda. Bittencourt Filho nos lembra que importantes lideranças fundamentalistas norte-americanas visitaram o Brasil na década de $1950^{26}$. Muito dinheiro de setores fundamentalistas dos Estados Unidos foi enviado para cá resultando na fundação de editoras, como a Betânia, e seminários como o Palavra da Vida. Esse ramo do protestantismo brasileiro embarcou alegremente no trem da Ditadura Militar, implantando uma espécie de Ditadura Eclesiástica nas principais denominações brasileiras àquela época ${ }^{27}$. E, finalmente, um terceiro grupo optou pelo caminho do reavivamento espiritual como solução para as mazelas nacionais. Foi este grupo que deu origem às igrejas carismáticas (Batista Renovada, Presbiteriana Renovada etc), rompimentos das antigas igrejas históricas.

\footnotetext{
${ }^{24}$ Talvez Moltmann seja o teólogo europeu mais "latino-americano". Suas freqüentes viagens à América Latina, sobretudo, à América Central deram a ele uma nova perspectiva em teologia. Isto fez com que ele tivesse relevante influência sobre os futuros formuladores da Teologia da Libertação.

${ }^{25}$ Cf. BITTENCOURT FILHO, José. Matriz Religiosa Brasileira. Religiosidade e mudança social. Petrópolis: Vozes, 2003. p. 125-126.

${ }^{26}$ Cf. BITTENCOURT FILHO, 2003, p. 126.

${ }^{27}$ Cf. ALVES, Rubem. Religião e Repressão. São Paulo: Teológica/Loyola, 2005.
} 
Rubem Alves, partidário do grupo progressista ecumênico afirma que a consciência desse setor se forjou a partir de três fontes: (a) influência da nova teologia européia (Karl Barth, Brunner, Moltmann etc); (b) a teologia bíblica deu a eles uma nova hermenêutica que se valia das ciências sociais e antropológicas e estudava o texto a partir de seu contexto; (c) o movimento ecumênico mundial e a nova consciência histórica que ele gerou ${ }^{28}$. Foi importante para esse grupo a criação da Confederação Evangélica Brasileira já em atuação desde 1934. A Confederação tornou-se uma espécie de reduto dos protestantes libertários e progressistas ${ }^{29}$. Sobre a Confederação, creio que vale à pena transcrever um trecho da obra de Bittencourt Filho, uma vez que esta Organização se apresenta provavelmente como a melhor tentativa de contextualização cultural e política do protestantismo nacional.

Em função dos projetos de cada um dos setores vinculados à Comissão [de Igreja e Sociedade], a Confederação chegou a possuir escritórios e funcionários em todo País. Ministrava cursos de formação de quadros de liderança, contemplando aspectos da realidade brasileira tais como a educação de adultos, questões fundiárias e administração de obras sociais. Chegou mesmo a cadastrar todas as organizações de assistência social das igrejas evangélicas no Brasil. [...] Ministrava cursos sobre "Responsabilidade Social"; programas de assistência social e promoção humana; apoiava e executava projetos, ao mesmo tempo em que [...] questionava o modelo assistencialista adotado pelas igrejas e sugeria debates de cunho teológico, científico e político. Em 1957 convocou [...] a Segunda Consulta, com um tema que se pretendia mais comprometido com a conjuntura nacional: "A Igreja e as Rápidas Transformações Sociais". O ápice desse processo deu-se com a convocação da Conferência do Nordeste (1962), com o lema "Cristo e o Processo Revolucionário Brasileiro". [...] A realização do evento na cidade de Recife, a cobertura da imprensa secular e religiosa, a presença de cientistas sociais renomados (entre outros, Gilberto Freyre e Celso Furtado), as recomendações dos grupos de estudos, a publicação de manifestos e a abordagem bíblicoteológica inovadora, foram alguns dos ingredientes que fizeram da Conferência o mais importante evento ecumênico que o Protestantismo Histórico já pôde promover. ${ }^{30}$

\footnotetext{
${ }^{28}$ Cf. ALVES, 2005, p. 258-259.

${ }^{29}$ Cf. BITTENCOURT FILHO, 2003, p. 141.

${ }^{30}$ Cf. BITTENCOURT FILHO, 2003, p. 141-142.
} 
Contudo, a CEB não foi a única experiência ecumênica e com forte consciência social promovida pelos protestantes. Vale destacar também a criação de outro Fórum em 1961, o ISAL - Igreja e Sociedade na América Latina. A idéia também era estabelecer reflexões teológicas inusitadas a partir do novo contexto industrial e urbano brasileiro, reunindo em seu corpo não apenas teólogos, mas também, cientistas sociais e políticos, antropólogos, filósofos etc, de várias partes da América Latina.

O projeto de ISAL, interdisciplinar, ecumênico e extremamente de vanguarda, vai atrair especialmente uma liderança jovem com profundas inquietações sobre a sociedade latino-americana, a natureza missionária da Igreja e a atuação do cristão no mundo. Esse foi o berço, primeiramente protestante e mais tarde também ecumênico, onde nasceu a teologia da libertação. ${ }^{31}$

Com o golpe militar de 1964, e a instalação de um regime ditatorial em algumas denominações evangélicas, os funcionários do Setor de Estudos e Responsabilidade Social da Confederação Evangélica Brasileira foram demitidos, um dos escritórios da Confederação foi invadido por agentes da repressão, documentos da Conferência do Nordeste foram destruídos, e a CEB teve um fim melancólico ${ }^{32}$. O ISAL também se desarticulou e acabou desaparecendo. A década de 1970 foi de terror para pastores e líderes progressistas com perseguições, cassações, prisão, exílio e até morte. Não obstante, a militância deles deu frutos.

A cooperação proporcionada pela CEB, ISAL e UCEB resultou nas experiências mais importantes do engajamento social do protestantismo brasileiro refletido na criação, anos depois, das chamadas "entidades ecumênicas de serviço", como o Centro Ecumênico de Informação (CEI), criado em 1965, que viria a se chamar posteriormente Centro Ecumênico de Documentação e Informação (CEDI) e a Coordenadoria Ecumênica de Serviço (CESE) que surgiu em 1973. ${ }^{33}$

\footnotetext{
${ }^{31}$ LONGUINI NETO, Luiz. O Novo Rosto da Missão: os movimentos ecumênico e evangelical no protestantismo latino-americana. Viçosa: Ultimato, 2002. p. 139-140.

${ }^{32}$ Cf. BITTENCOURT FILHO, 2003, p. 144-145.

${ }^{33} \mathrm{CONRADO}$, Flávio. Igreja e sociedade em meio às rápidas transformações sociais. Disponível em: $<$ http://www.ultimato.com.br/?pg=show_artigos\&secMestre=2082\&sec=2110\&num_ edicao $=310>$. Acesso em: 13 de janeiro de 2010 .
} 
Poderíamos acrescentar a criação do CLAI - Conselho Latino-Americano de Igrejas e do CONIC - Conselho Nacional de Igrejas Cristãs, ambos ligados ao CMI - Conselho Mundial de Igrejas. Enquanto isso, as denominações históricas e pentecostais, grosso modo, permaneceram com a mesma ideologia dos missionários do século XIX, professando uma cultura muito mais anglo-saxônica do que brasileira. A década de 1970 também foi a década de estagnação no crescimento das denominações históricas. Diante dos fatos, "o protestantismo histórico se divide entre a opção 'ecumênica', a opção 'pentecostal-carismática', a opção 'tradicional-fundamentalista' ou a opção 'evangelical-progressista'". ${ }^{34}$ Uma alternativa de articulação entre Evangelho e Responsabilidade Social mais à direita da posição ecumênica foi a representada pelos evangelicais com a elaboração da Teologia da Missão Integral pelo teólogo equatoriano C. Renné Padilla. A Missão Integral, articulada a partir dos Congressos Latino-Americanos de Evangelização (CLADE) e inspirada no Pacto de Lausanne girava em torno do eixo "o evangelho todo, para o homem todo, para todos os homens". Continua ainda hoje atuante em várias partes da América Latina.

Concluindo: a cultura brasileira, por motivos distintos, foi rejeitada tanto pelo protestantismo de imigração quanto pelo protestantismo de missão. No caso das igrejas de imigração pelos fortes laços que estas mantiveram com suas pátrias de origem como caminho de preservação da própria identidade. Já as igrejas de missão, pelo viés puritano-pietista. Desse modo, não podemos falar de uma teologia brasileira nas primeiras décadas de presença protestante no País. O que aconteceu foi o transplante de teologias estrangeiras, européia e norte-americana, para as terras brasileiras. E, quando se tentou articular, no ambiente protestante, uma teologia brasileira, ou seja, uma teologia a partir da realidade nacional e que contribuísse de alguma forma para a melhoria de condições de vida do povo, Seminários foram fechados, os mentores foram cassados, demitidos e expulsos de suas denominações. Em alguns casos ocorreram prisões de pastores, outros tiveram que partir para o exílio e também aconteceram casos de assassinato pela Ditadura, como a de Paulo Wright deputado cassado, irmão do Pr. Jaime Wright, desaparecido em 1973.

O que permaneceu quase que de forma monolítica, foi a velha teologia puritano-pietista já nossa conhecida. Essa teologia evangélica é assim caracterizada pelo teólogo metodista Albert Outler:

\footnotetext{
${ }^{34}$ CONRADO, Flávio. Igreja e sociedade em meio às rápidas transformações sociais. Disponível em: $<$ http://www.ultimato.com.br/?pg=show_artigos\&secMestre=2082\&sec=2110\&num_ edicao $=310>$. Acesso em: 13 de janeiro de 2010 .
} 
O traço mais destacado [...] é seu fervor emocional, concentrado sempre nestes dois pontos, e quase só neles: 1) a salvação: libertação do pecado e da culpa (do inferno e da condenação) e 2) uma moralidade pessoal "autoinibidora", [Este é] o triunfo efetivo no Novo Mundo do "protestantismo radical" tão severamente reprimido na Europa [...]. Essa tradição protestante era majoritariamente "montanista" em sua eclesiologia (igreja "baixa", igreja "livre"): anti-sacerdotal, anti-sacramental, antiintelectualista. Ela fazia uma distinção pejorativa entre teologia especulativa e fé existencial. Suspeitava de um clero erudito. Considerava a conversão, e não a iniciação, o clímax da experiência cristã. Insistia na religião pessoal como a única essência verdadeira do Cristianismo. ${ }^{35}$

Ao apontarmos para a tendência isolacionista do protestantismo de imigração não significa desconsiderar a necessidade e a liberdade de determinados grupos cultivarem suas raízes culturais, seus símbolos e sua origem histórica. Significa, isto sim, alertarmos para o perigo de, na celebração étnica, esses grupos estabelecerem com o restante da sociedade uma relação de domínio (vide o apartheid na África do Sul) ou, pelo menos, de fechamento em sua própria cultura, numa atitude auto-satisfatória.

A universalidade da história da salvação não é a dissolução dos espaços específicos, étnicos e diferenciados. Não é uma negação da etnicidade como criação de Deus, como espaço de encarnação do evangelho de Jesus Cristo. $\dot{E}$, isso sim, a negação do espaço fechado sobre si mesmo. O que o apóstolo Paulo rejeita é "a etnicidade como mérito". A universalidade da graça não é a eliminação de raça, sexo ou condição social, e sim sua libertação para o exercício do amor. (grifo nosso) ${ }^{36}$

E, ao apontarmos para as marcas puritano-pietistas, tipicamente norte-americanas, do protestantismo de missão, não significa afirmar que isto por si só representa irrelevância social e histórica. As marcas do evangelicalismo norte-americano não desembocam necessariamente nem tão-somente em equívocos e preconceitos culturais. Entretanto, quando tal referencial torna-se um fim em si mesmo, não há espaço para o reconhecimento do outro em sua alteridade, do seu valor intrínseco e da beleza de sua cultura. Neste ponto,

\footnotetext{
${ }^{35}$ BONINO, José Miguez. Rostos do Protestantismo Latino-Americano. São Leopoldo: EST/ Sinodal, 2003, p. 85.

${ }^{36}$ BONINO, 2003, p. 95.
} 
a chegada das missões protestantes ao Brasil lembra a mesma relação mantida pelos missionários católicos no século XVI com os ameríndios. Ambos não reconheceram a alteridade do povo que aqui se encontrava. O projeto colonialista estava presente em ambos: nestes um colonialismo geográfico, físico e econômico; naqueles um colonialismo cultural. O setor ecumênico do protestantismo brasileiro representou uma saudável alternativa de superação da antropologia dualista platônica com a articulação entre Igreja e Sociedade e com seu engajamento social.

\section{Referências Bibliográficas}

ALVES, Rubem. Dogmatismo e Tolerância. São Paulo: Paulinas, 1982. . O que é Religião. São Paulo: Brasiliense, 1981. . Religião e Repressão. São Paulo: Teológica/Loyola, 2005.

BITTENCOURT FILHO, José. Matriz Religiosa Brasileira. Religiosidade e mudança social. Petrópolis: Vozes, 2003.

BONINO, José Miguez. Rostos do Protestantismo Latino-Americano. São Leopoldo: EST/Sinodal, 2003.

CAVALCANTE, Ronaldo. A Cidade e o Gueto. Introdução a uma Teologia Pública Protestante e o desafio do neofundamentalismo evangélico no Brasil. São Paulo: Fonte Editorial, 2010.

CONRADO, Flávio. Igreja e sociedade em meio às rápidas transformações sociais. Disponível em: <http://www.ultimato.com.br/?pg=show_artigo $\mathrm{s} \& \sec$ Mestre $=2082 \& \mathrm{sec}=2110 \&$ num_edicao $=310>$. Acesso em: $13 \mathrm{de}$ janeiro de 2010.

DASILIO, Derval. A Teologia da Libertação e o Protestantismo Brasileiro. p. 4. Trabalho não publicado.

GONZALEZ, Justo L. Uma História do Pensamento Cristão. Da Reforma Protestante ao Século 20. Vol. 3. São Paulo: Cultura Cristã, 2004.

HABERMAS, Jürgen. Entre Naturalismo e Religião. Estudos Filosóficos. Rio de Janeiro: Tempo Brasileiro, 2007.

HENDERS, Helmut. "É a Tarefa da Igreja Motivar a Sociedade para a Ação": Do contínuo significado de Walter Rauschenbusch. In: Simpósio 48. São Paulo: ASTE, 2008.

KLEIN, Carlos Jeremias. A Teologia Liberal e a Modernidade. In: Etienne Alfred Higuet (org.). Teologia e Modernidade. São Paulo: Fonte Editorial, 2005. 
LONGUINI NETO, Luiz. O Novo Rosto da Missão: os movimentos ecumênico e evangelical no protestantismo latino-americano. Viçosa: Ultimato, 2002. MENDONÇA, Antônio Gouvêa. O Celeste Porvir: A Inserção do Protestantismo no Brasil. São Paulo: Pendão Real/ASTE/Ciências da Religião, 1995.

OLSON, Roger. História da Teologia Cristã. 2.000 anos de tradição e reformas. São Paulo: Vida, 2001.

ROSA, Wanderley. ODualismona Teologia Cristã. A deformação da antropologia bíblica e suas conseqüências. São Paulo: Fonte Editorial, 2010.

TILLICH, Paul. História do Pensamento Cristão. São Paulo: ASTE, 2000.

WALKER, Wiliston. História da Igreja Cristã. Volumes 1 e 2. São Paulo: ASTE, 2006.

\section{Wanderley Pereira da Rosa}

Graduado em Teologia pelo Seminário Presbiteriano

Rev. José Manoel da Conceição (São Paulo, 1991)

Licenciado em Filosofia pela Universidade Federal do Espírito Santo (Vitória, 2001)

Mestre em Teologia pela EST (São Leopoldo, 2010)

Doutorando em Teologia pela PUC/RJ

Diretor-Geral da Faculdade Unida de Vitória onde também leciona História do Cristianismo

Artigo Recebido em 23/08/2011

Artigo Aprovado em 07/11/2011 